IZA DP No. 7477

Can Contracts Signal Social Norms?

Experimental Evidence

Anastasia Danilov

Dirk Sliwka

June 2013 


\title{
Can Contracts Signal Social Norms? Experimental Evidence
}

\author{
Anastasia Danilov \\ University of Cologne \\ Dirk Sliwka \\ University of Cologne \\ and IZA
}
Discussion Paper No. 7477
June 2013

\author{
IZA \\ P.O. Box 7240 \\ 53072 Bonn \\ Germany \\ Phone: +49-228-3894-0 \\ Fax: +49-228-3894-180 \\ E-mail: iza@iza.org
}

Any opinions expressed here are those of the author(s) and not those of IZA. Research published in this series may include views on policy, but the institute itself takes no institutional policy positions. The IZA research network is committed to the IZA Guiding Principles of Research Integrity.

The Institute for the Study of Labor (IZA) in Bonn is a local and virtual international research center and a place of communication between science, politics and business. IZA is an independent nonprofit organization supported by Deutsche Post Foundation. The center is associated with the University of Bonn and offers a stimulating research environment through its international network, workshops and conferences, data service, project support, research visits and doctoral program. IZA engages in (i) original and internationally competitive research in all fields of labor economics, (ii) development of policy concepts, and (iii) dissemination of research results and concepts to the interested public.

IZA Discussion Papers often represent preliminary work and are circulated to encourage discussion. Citation of such a paper should account for its provisional character. A revised version may be available directly from the author. 


\begin{abstract}

\section{Can Contracts Signal Social Norms? Experimental Evidence}

We investigate whether incentive schemes signal social norms and thus affect behavior beyond their direct economic consequences. A principal-agent experiment is studied in which prior to contract choice principals are informed about past actions of other agents and thus have more information about "norms of behavior". Compared to a setting with uninformed principals agents exert nearly $50 \%$ higher efforts under a fixed wage contract when an informed principal had chosen this contract. Apparently the informed principal's choice signals a norm not to exploit the trust which leads to more trustworthy behavior. This mechanism's robustness is explored in further experiments.
\end{abstract}

JEL Classification: D03, C91, D86

Keywords: social norms, contracts, incentives, signaling, experiments

Corresponding author:

Dirk Sliwka

Faculty of Management, Economics, and Social Sciences

University of Cologne

Albertus-Magnus-Platz

50923 Cologne

Germany

E-mail: dirk.sliwka@uni-koeln.de 


\section{Introduction}

In recent years the notion that social norms matter for behavior has gained considerable attention also in economics. ${ }^{1}$ Indeed, there is now substantial evidence that individuals are affected in their choices by observed behavior of others in an identical situation. ${ }^{2}$ Many individuals tend to avoid deviations from prevalent norms of behavior, for instance, as these deviations may cause negative emotions such as remorse or shame.

But often individuals are faced with situation where there is uncertainty about the prevalent norms. Consider for example an employee who has just joined an organization and may be uncertain about the expected effort and working time, whether it is acceptable to use the internet for private purposes in the office, or to what extent it is expected to support colleagues. A very natural reaction for this employee should be to gather information about the behavior of others in the same situation that allows to detect a potential norm of conduct. This may be easy for observable actions (such as working time), it may, however, be very difficult for other unobservable actions which are crucial for the performance of the organization (such as productively spent working time). Even after several years in the same organization this employee might be unable to assess the behavior of her colleagues in some situations with complete certainty and may have to rely on additional information or clues.

On the other hand, owners or managers often have means, such as active monitoring systems, performance key figures, or employee surveys, to gain a deeper understanding about existing work norms and attitudes in their organization. Even when direct information about individual behavior is not

\footnotetext{
1 See for instance Akerlof (1980), Elster (1989), Bernheim (1994), Lindbeck, Nyberg and Weibull (1999), Kübler (2001), Fehr, Fischbacher and Gächter (2002), Fehr and Fischbacher (2004a), Fischer and Huddart (2005), Bicchieri (2006), Krupka and Weber (2009), Krupka, Leider, and Jiang (2011). See also Young (2008) for an overview.

2 Examples are Ichino and Maggi (2000), Clark (2003), Stutzer and Lalive (2004), Bradler, Dur, Neckermann and Non (2013).
} 
available, they may be able to infer "average behavior" from other sources such as accounting key figures. When designing management tools such as incentive schemes or monitoring technologies managers will naturally use this information about observed behavioral patterns. For instance, when observing an under-provision of some action, a principal may choose to use higher powered incentives for this action or impose tighter monitoring. But one important effect of these kinds of regulations may be overlooked, namely, that such interventions may convey information about the prevalent norms in an organization - and this in turn can have an indirect effect on employees' actions as perceptions about the behavior of others is altered. Sliwka (2007), Friebel and Schnedler (2011), van der Weele (2012), and Bénabou and Tirole (2012) have indeed recently shown in formal economic models that contract choices may signal information about the actions of other agents and thus create indirect effects on behavior.

We explore this idea that contracts can signal social norms in a set of laboratory experiments. The key idea of the mechanism we study is most closely related to the theoretical approach by Sliwka (2007). Suppose that agents can have a preference for conformity as their behavior is influenced by their beliefs about the behavior of others. Conformists act prosocially if they believe that many other agents do so. If now a principal who has more information about the distribution of types in the organization proposes a specific contract, this choice may reveal information about the behavior of others and thus the prevalent norms in the organization. In particular, when a principal proposes a pure fixed wage contract, she is apparently confident that most agents will not shirk - and in turn conformists' inclination to shirk should be reduced. On the other hand, the choice of a performance contingent contract or a tight monitoring scheme may reveal the principal's pessimism about the behavior of the agents - and in turn increases conformists' 
willingness to act more selfishly. ${ }^{3}$ As there are always selfish individuals around signaling by choosing a fixed wage or not using a monitoring technology is costly to the principal and therefore can make the signal credible: In an organization with many selfish agents principals would lose a lot when trusting their employees and thus refrain from doing so.

To study this idea and its implications in detail we conducted several lab experiments. In our first experiment we implement a very simple one shot principal-agent game. In the Baseline treatment, principals can choose between a fixed wage contract and a performance-based contract. Each principal is matched to an agent who then determines his effort. We elicit the agents' efforts for both contract types using the strategy method. ${ }^{4}$ In the Norms treatment, we replicate this Baseline treatment with one addition: We show the principals a table containing the efforts chosen by participants in a preceding baseline session and we inform the agents that their principals have seen such a contributions table (without showing the agents its content). Hence, the treatment intervention is rather weak on the agents' side: they do not have more direct information about the behavior of others - but they know that the principals had this information prior to their contract choice.

It turns out that this treatment variation has a substantial effect on the chosen efforts. When a fixed wage is chosen by an informed principal, efforts are roughly 50\% higher than in the Baseline treatment even though payoff functions for principals and agents are completely identical in both treatments. Agents indeed become much more trustworthy when they know that the principal who decided not to use the performance contingent contract made this decision being well informed about the behavior of other agents in the same situation.

\footnotetext{
3 Several other theoretical models explore the detrimental effects of sanctions or performance contingent wage schemes and give potential (behavioral) economic explanations (see, for instance, Benabou and Tirole 2003, 2006; Ellingsen and Johannesson 2008). For a broader overview on the issue see Bowles (2008).

${ }^{4}$ See Selten (1967).
} 
The mechanism described in the above rests on two arguments. First of all, the contract choice must convey information about what the principal saw and thus affect beliefs about the behavior of others. Second, changes in the beliefs about the behavior of others must affect the agents' own behavior. We conducted further experiments to test these steps in turn, showing that (i) beliefs about the prior information of the principal are indeed substantially affected by knowledge of her contract choice, (ii) agents choose different actions when learning selected choices of other agents in the same situation. ${ }^{5}$

The suggested mechanism has another important implication as the "signaling value" of the contract choice should differ between different contexts. To understand this point consider a situation in which a principal can again choose between two regimes, one in which she trusts the agent and another one in which she monitors him closely. When monitoring is very effective, the latter regime is rather attractive for the principal. Then choosing to trust by intentionally not using the monitoring technology is a particularly strong signal about the prevalent norm: the principal would only forgo the opportunity to monitor the agent when she observed that most employees do not shirk when being trusted. When conformism matters being trusted by an informed principal should then indeed lead to more trustworthy behavior. When, on the other hand, the monitoring technology is rather imprecise or costly, not using this technology is a weaker signal about the trustworthiness of others. But more importantly, being monitored is then a bad signal on the prevailing norm, as only a principals who observed many shirking agents would still use a rather inefficient monitoring technology. In such a context we should observe that agents reduce prosocial behavior when being monitored by informed principals. In other words, the less attractive and thus the less

\footnotetext{
5 The latter is well in line with previous studies on "social history effects". For instance, Berg, Dickhaut and McCabe (1995) show that information about behavior of others has a positive effect on reciprocity in an investment game. Bardsley and Sausgruber (2005), Bicchieri and Xiao (2009) and Gächter, Nosenzo and Sefton (2012) find a positive correlation between contributions in public goods, dictator and gift-exchange games and information on decisions of unrelated individuals in the same situation.
} 
frequent is a contract choice, the stronger should be agents' norm-based reaction to it, as this choice induces a stronger revision of prior beliefs about the behavior of others.

In order to investigate this we conducted two further experiments. First, we replicated Falk and Kosfeld's (2006) "Costs of Control” experiment where the principal can decide whether or not to impose a moderate lower bound on agent's effort contributions in a modified dictator game. As in our previous experiment we varied whether the principal was informed about the behavior of agents in a prior session. Because the imposable restriction on effort is rather low (10 in an action space between 0 and 120), using it should now reveal that the principal observed many selfish agents who chose efforts below the boundary. If conformity matters this should lead to lower efforts. On the other hand, not imposing this weak restriction should not be a particularly strong signal of trustworthy behavior of others. Indeed, we find that having an informed principal here does not alter agents' reaction to being trusted but lowers contributions when principals impose a restriction.

As a further test of this argument we go back to our initial setting and run additional treatments varying the attractiveness of the performance contingent wage for the principal without changing the agent's payoff structure. We do this by simply imposing a fixed cost the principal has to incur when choosing a performance contingent contract. As now the fixed wage is relatively more attractive than in the first experiment it should be chosen by more of the informed principals (i.e. even when they have observed less prosocial behavior). In turn, the positive signaling value of the fixed wage contract should become weaker. But, by the same token, the choice of the performance contingent wage should now become a more negative signal about the norm. Well in line with this reasoning we indeed observe that while the fixed wage still leads to significantly higher efforts when being proposed by an informed rather than an uninformed principal, the effort increase is weaker. But moreover, the performance-contingent wage now leads to substantially lower 
efforts when chosen by an informed principal. Hence, we can conclude that the relative attractiveness of the contract affects the agents' inference about the social norm and thus indirectly influences behavior.

This study is related to some recent contributions on the interaction of social norms and contracts. According to the model by Benabou and Tirole (2012) norms arise not because of preferences for conformity but because the behavior of others influences how publicly observed actions affect social esteem. In their model agents differ with respect to their intrinsic motivation to choose a certain prosocial action and have a preference to be esteemed, i.e. that others perceive them to be intrinsically motivated. An observer's perceptions of a certain act depends now on the equilibrium strategies chosen by all agents in the population - hence, social norms arise because observed actions have different signaling values conditional on the strategies of other agents. Similar to Sliwka (2007) changes in extrinsic incentives may reveal a designer's private information on the distribution of types and therefore affect the way in which outside observers interpret the chosen actions. In the models by Friebel and Schnedler (2011) and van der Weele (2012) there is a complementarity between efforts of different agents, and therefore information about the behavior of others is directly valuable to improve coordination. Galbiati, Schlag, and Van der Weele (2011) study behavior in a twice repeated "weakest link"-coordination game experiment in which there are technological complementarities. They compare sanctions which are exogenously imposed after the first round unconditional on previous behavior to that of sanctions that are endogenously imposed by a subject who observes previous behavior and benefits from high levels of coordination and find that players who made high contributions in the first round contributed less under endogenous sanctions in the second round.

In our set-up, the behavior of agents is not publicly observable, there is no interdependence in production between the agents, and the agents themselves do not learn the behavior of others. We show that contract choices reveal 
information on norms and this matters for behavior even when individual choices remain unobservable and in the absence of any technological interdependence. Hence, the observed effects can neither be driven by image concerns nor by technological complementarities, but are well in line with the idea that people can have an intrinsic preference for norm compliance.

The remainder of the paper is organized as follows: In the next section we present the design and results of our core experimental setting. In section III we study the two steps of the proposed mechanism further by sheding light on (i) the effect of contract choices on beliefs and (ii) exogenously manipulated beliefs on behavior. In section IV we study the mechanism in a different context using Falk and Kosfeld (2006) "Costs of Control" experiment and vary the signaling value of the contract in our core experimental setting. Section V concludes.

\section{Contract Choice Experiment}

\section{A. Design and Procedure}

Our baseline design is a simple one shot principal-agent experiment. A principal is matched to an agent and has to make a choice between two different specific contracts. Then the agent exerts an effort level which affects a binary outcome distribution determining the principal's profit. At the beginning of the experiment all participants receive an endowment of $6 €$. Subjects are randomly matched in pairs, where one subject is assigned the role of a principal (labeled as employer) and other to the role of an agent (employee). The principal chooses between either a fixed wage contract (labeled as trust compensation) or performance-based bonus contract (contingent compensation) for her agent. The agent chooses an effort level $e \in[0,100]$ at private costs of $c(e)=e^{2} / 1200$. This effort level determines the probability that the principal receives a high payoff, i.e. with probability $e$ she earns $12 €$ and nothing otherwise. The agents are explicitly told that the 
principals cannot observe their efforts but only the project success. Under the trust contract the principal pays an unconditional wage of $5 €$. Under the contingent contract the agent receives $5 €$ only if the principal earns the high payoff of $12 €$ and nothing otherwise. ${ }^{6}$

Efforts for both contract types are elicited using the strategy method such that each agent has to state the effort level for both contract types before learning about the principal's choice. ${ }^{7}$ After all choices are made, the payoffs are computed based on the respective choices that have been made by principal and agent.

We designed two treatments henceforth called the Baseline and the Norms treatment. Both treatments are identical with one exception: An additional text is introduced on the decision screen in the Norms treatment and the principals see real decisions of all 10 agents from a previous session of the Baseline treatment. The agents know that principals have this information without knowing its content. ${ }^{8}$ The payoff functions for both principal and agent stay completely identical. Hence, from the agents' perspective the treatment intervention varies only the fact that the principals are better informed about the behavior of other agents in the same population. Thus, any changes in agents' behavior must be driven by their awareness that the principals had more information prior to the contract choice.

All decisions were anonymous and no communication was permitted during the experiment. All subjects participated only once. At the end, they were informed about the achieved outcome and their payoffs and received an additional show-up fee of $2.50 €$. Average earnings were $10.24 €$. The sessions

\footnotetext{
6 The second-best effort (maximizing the individual payoff) is 0 for the trust and 30 for the contingent contract and the first-best effort (maximizing the joint payoff) is 72 in both cases. Under the trust contract principal and agent earned equal payoffs at an effort of 59 and the principal does not make losses at effort levels of at least 42.

7 Agents had access to an on-screen computation tool, where they could insert effort values for a particular contract, and learn the costs of effort and (expected) payoffs for both parties. They could use this tool for as many trials as they wanted before determining their final decision.

${ }^{8}$ Principals see a table with 10 columns and 2 rows showing the efforts chosen by agents in a previous session of the Baseline treatment. To ascertain that agents understand the principal's information structure agents see the same table but with "xx" instead of the actual efforts (see instructions in the Appendix 2).
} 
lasted about one hour. The experiment was conducted in the Laboratory for Experimental Research of University of Cologne using experimental software zTree (Fischbacher, 2007). In total 120 participants - mostly students - were recruited via ORSEE (Greiner, 2004). All participants received identical onscreen instructions reported in the Appendix 2. Before proceeding to the decision stage subjects had to complete a short quiz on the structure of the experiment and the computation of payoffs. Only after answering correctly they could proceed to the decision stage. 60 subjects took part in each of the two treatments.

\section{B. Results}

Our key hypothesis is that agents react differently to an identical contract when they know that the contract has been chosen by a principal who is informed about the behavior of other agents in an identical situation. In particular, we expect agents to choose a higher effort under the "trust"contract if this is proposed by an informed principal. The reason is that in this case the contract choice should reveal that apparently many other agents in the same situation did not shirk as otherwise the principal would not have proposed this contract. And if social norms matter this should indeed have an impact on the actual effort choices and lead to higher efforts under the trust contract. Norms should play a weaker role under the contingent contract as here even selfish agents have an incentive to exert effort. 


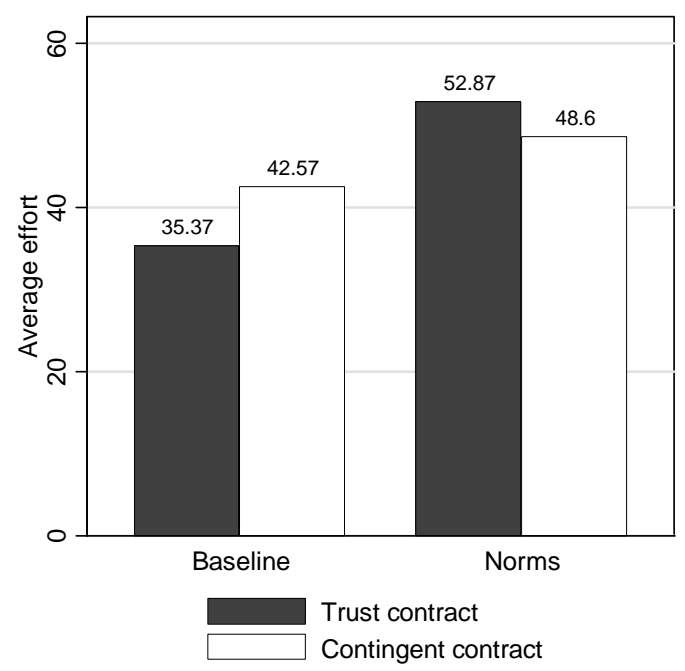

FIGURE 1: AVERAGE EFFORTS FOR THE TRUST CONTRACT AND CONTINGENT CONTRACT

Figure 1 shows the average efforts for both contracts in the Baseline and the Norms treatment. Indeed we observe that the agents' reaction to the trust contract differs substantially between the two treatments: The average effort in the Baseline treatment is 35.37 but raises by nearly $50 \%$ to 52.87 in the Norms treatment. ${ }^{9}$ This difference is statistically significant at the $5 \%$ level $\left(p=0.0169\right.$, one-sided Mann-Whitney U test). ${ }^{10}$ Hence, agents indeed provide significantly more effort when the trust contract is chosen by an informed principal.

In contrast to the trust contract, we do not observe a significant difference in efforts for the contingent contract: Here the average effort is 42.57 in the Baseline and 48.6 in the Norms treatment but this difference is not significant $(p=0.2161$, one-sided MWU test $)$.

\footnotetext{
9 See Table A1 in the Appendix 1 for the overview of descriptive statistics.

${ }^{10}$ We apply one-sided tests when we have a clear initial directed hypothesis and two-sided tests otherwise.
} 

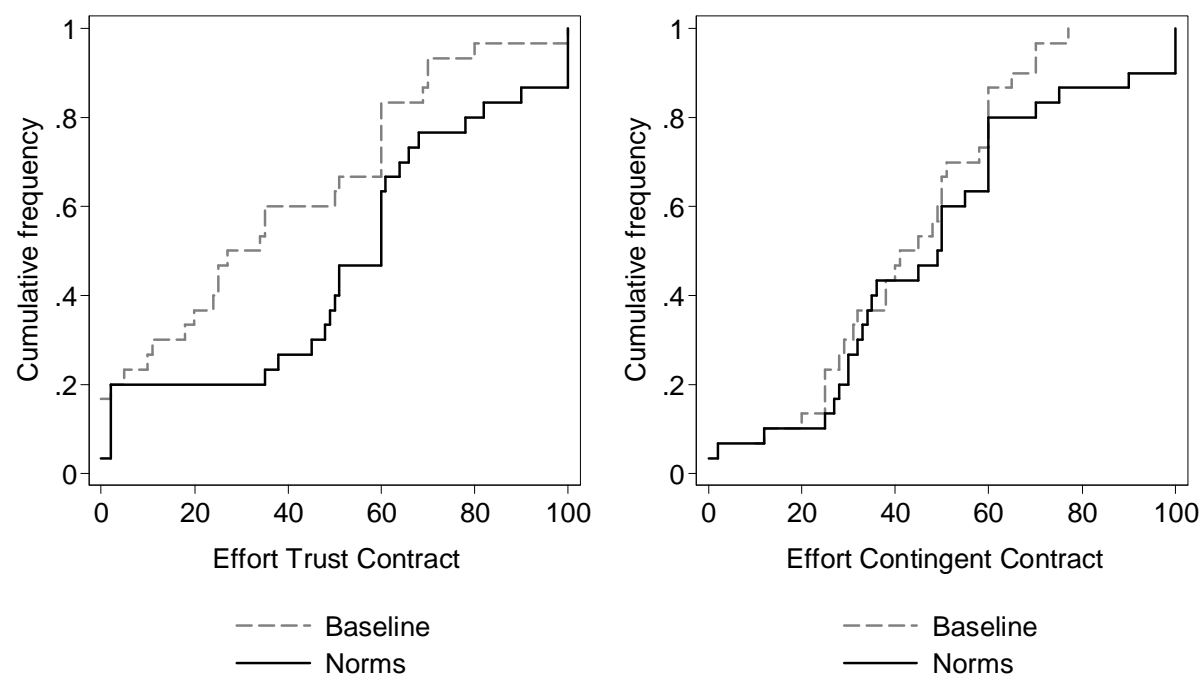

FIGURE 2: EFFORT DISTRIBUTIONS IN THE BASELINE AND NORMS TREATMENTS

Figure 2 shows the cumulative distribution of effort choices for the trust contract (left panel) and the contingent contract (right panel). It is interesting to note that the fraction of agents choosing efforts below ${ }^{11} 3$ under the trust contract is exactly $20 \%$ in both treatments. Also the fraction of agents who chose the nearly payoff equalizing value of $60(16 \%)$ is virtually identical (see left panel in Figure 2). But while nearly 33\% of the agents choose an effort between 3 and 34 in the Baseline treatment, not a single agent chose an effort level in this interval in the Norms treatment $(p=0.0008$, two-sided Fisher's exact test). The Norms treatment, hence, leads to a shift from these not entirely selfish but still low effort levels to the upper tails of the distribution. The fraction of purely selfish agents remains virtually unchanged.

Although the behavior of agents under the trust contract is more favorable in the Norms treatment, the trust contract is here relatively expensive and still risky from a principal's perspective. Indeed, most principals choose the

\footnotetext{
11 Note that due to the convexity of the cost function these very small efforts have costs of 0 .
} 
incentive contract as it is less costly and leads to a more certain outcome. We find that in the Norms treatment only $6 \%$ of principals offer a trust contract. This is mainly due to the fact that the principals observe rather selfish behavior under this contract form (the displayed effort under the trust contract is by on average $24 \%$ lower then the effort under the contingent contract). Expected payoffs of principals under the trust contract in the Baseline treatment are 5.24€. This increases to $7.34 €$ in the Norms treatment ( $p=0.0169$, one-sided MWU test) but are still smaller than the profits of $9.40 €$ under the contingent contract in this setting $(p=0.001$, two-sided Wilcoxon signed-rank test). However, while overall welfare is significantly smaller under a trust contract in the baseline setting (14.54€ compared to $15.21 €, p=0.0324)$, the trust contract achieves a nearly identical total welfare level as the contingent contract in the Norms treatment (15.32€ compared to 15.29€, $p=0.5284$, both two-sided WSR test). To investigate the robustness of the mechanism when the trust contract is a more attractive choice we study additional treatments which are reported in section IV.

Overall we find substantial support for the key hypothesis that contracts can indeed signal social norms and, in turn affect behavior beyond the direct incentive effects. Moreover, these effects are sizeable and result in a substantially improved performance under fixed wage contracts which are risky in one shot interactions without strong cooperative social norms. To gain a deeper understanding of the behavioral mechanisms at work, we report results from additional experiments in the next section.

\section{Disentangling the Signaling Mechanism}

As laid out in the above, the suggested mechanism rests on two premises: first of all, the contract choice must convey information about what the principal has seen prior to her choice and thus affect beliefs about the behavior of others. Second, information about the behavior of others must affect the 
agents' own behavior. We now test these two hypotheses in turn in additional experiments.

\section{A. Contract Choice and Beliefs}

In our previous Norms treatment we intentionally decided not to elicit agents' beliefs about what principals have seen in order to avoid experimenter demand effects. ${ }^{12}$ Hence, we conducted a separate (online) experiment purely designed to elicit incentivized beliefs about information and behavior in our first experiment. The aim is to investigate whether and how information about the contract choice of an informed principal affects beliefs about the behavior of agents observed by this principal.

Design and Procedure - We conducted three different treatments with separate sets of new subjects for each treatment. In treatment 1 (Baseline) of this belief elicitation experiment, instructions from the Baseline treatment of the Contract Choice Experiment were presented to a new sample of 60 subjects. They were informed that the Baseline treatment had been carried out before and that their task is to estimate the behavior of subjects in the earlier experiment. In particular, they had to estimate the average effort contributions for the trust and the contingent contract. In a third question, we asked participants to estimate the fraction of principals who chose the trust contract.

In the two further treatments 2 (Contingent) and 3 (Trust) subjects received the instructions from the Norms treatment. They had to estimate the information a principal had when selecting one of the two contracts. In both cases subjects received the instructions for the Norms treatment. In treatment 2 subjects had to estimate the average efforts actually observed by a principal randomly chosen among those who had selected the contingent contract. In

\footnotetext{
12 When eliciting beliefs before effort choices we would have guided agents to focus on beliefs and may have created experimenter demand effects inducing our mechanism. When eliciting them ex-post they may be guided by "false consensus" effects. See Costa-Gomes, Huck, and Weizsäcker (2012) for a discussion on the endogeneity of beliefs.
} 
treatment 3 they had to estimate the average efforts observed by a principal who had chosen the trust contract. In each of these two treatments subjects had to state two numbers - one for the average efforts under the trust contract and one for average efforts under the contingent contract - both observed by this particular principal prior to his choice. ${ }^{13} \mathrm{~A}$ comparison between these treatments allows us to investigate to what extent the actual contract choice of a principal affects beliefs about this principal's knowledge on the behavior of others observed prior to the choice. The key hypothesis is that subjects who have to estimate the prior information seen by a principal who actually proposed a fixed wage contract should on average believe that this principal has observed higher efforts under this contract type than a principal who actually chose a contingent contract. Moreover, we can investigate which observed contract choice leads to a stronger revision of beliefs relative to the ex-ante beliefs without knowledge about a principal's choice (i.e. those elicited in treatment 1 of this belief elicitation experiment).

In all three treatments subjects were paid for the correctness of their beliefs according to the quadratic scoring rule: they earned $3 €$ minus 1 cent for each unit of quadratic deviation from the respective true value. The subjects received nothing for answers with a deviation of more than 17 points from the true value. The experiment was conducted online and participants were paid per bank transfer or with amazon.de vouchers. Each subject participated only once and had not taken part in any of the prior treatments.

Results - We compare the individual difference in the estimates for the efforts under the contingent and trust contract thus obtaining one independent observation per participant. Figure 3 plots these differences for the three

\footnotetext{
13 After showing the instructions of the Norms treatment and asking test question to ensure that agents understood the setting, the subjects received the following statement: "We have randomly drawn one of the prior participants in the role of an employer. This employer has observed contributions of 10 employees from the prior experiment for both the trust and the contingent contract. This employer has chosen the [Treatment 2:] contingent contract / [Treatment 3:] trust wage after having seen the table of the form shown in the above. What is your best estimate about the average effort under the trust contract in the table above? What is your best estimate about the average effort under the contingent contract in the table above?"
} 
treatments. $^{14}$ All three differences are significantly different from zero $(p=0.0008, p=0.0018, p=0.0178$, two-sided WSR test $)$.

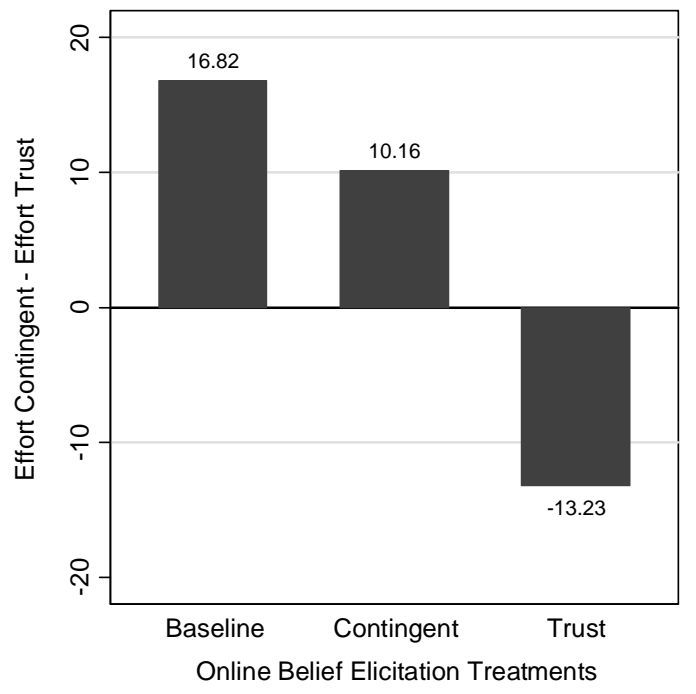

FIGURE 3: AVERAGE DIFFERENCES IN ESTIMATED EFFORTS

The first bar shows the difference in elicited beliefs for the Baseline treatment. In line with the actual behavioral pattern participants estimate that agents exerted higher efforts under the contingent contract. ${ }^{15}$ The same holds for the treatment where participants estimate what principals had seen before proposing a contingent contract. The within-subject difference in beliefs is not significantly different between the Contingent and the Baseline treatment ( $p=0.2007$ two-sided MWU test). But the difference becomes negative when participants estimate what principals had observed before proposing the trust contract. Here the subjects expect higher effort under the trust contract than under the contingent contract. This "belief spread" is significantly different from both other treatments (both $p \leq 0.0002$, two-sided MWU test).

\footnotetext{
14 See also Table A1 in the Appendix 1 for descriptive statistics on the means.

15 Although, in the Baseline treatment the subjects came close to the average effort for the trust contract, they significantly overestimate the effort under the contingent contract ( $p=0.9413$ and $p<0.0001$, two-sided WSR test).
} 
Hence, the contract choice indeed affects the beliefs about prior information obtained by the principal. But more importantly, after observing a principal who proposed a contingent contract beliefs are qualitatively closer to the baseline beliefs. In this sense, a trust contract is a more surprising signal (as it leads to a stronger revision of baseline beliefs) as compared to a contingent contract. ${ }^{16}$ This may explain also why we observe such a strong positive effect of norms under the trust contract but no negative reaction of norms under the contingent contract. When an informed principal offers a trust contract this is apparently a strong signal of trustworthiness of the population while a contingent contract does not come as a surprise and therefore yields no negative reaction. We explore this issue in more detail and further experiments in section IV.

\section{B. Effects of Observed Behavior}

Next we explore to what extent explicit information about actions of others affect agents' decisions. Note that this conjecture is well in line with a larger number of experiments on "social history effects" 17 where knowledge about past behavior of others in the same situation affects choices. We investigate whether and to what extent this is the case also in our setting by designing a very simple experiment in which we induce different norms of behavior in a rather straightforward way.

Design and Procedure - The design of this experiment is similar to our Baseline treatment in the Contract Choice Experiment. Subjects are matched in pairs and assigned roles of either principal (employer) or agent (employee). Again, principals choose a fixed or performance-contigent wage. The agents have to decide on effort levels for each contract form. The parameters are

\footnotetext{
${ }^{16}$ We also asked participants in the treatment 1 to estimate the fraction of employers who chose the trust contract. Subjects believe that on average $23.38 \%$ of the employers had offered the trust pay contract which is larger than actual choices of the trust contract (about 10\%).

17 See for example Berg, Dickhaut and McCabe (1995), Bardsley and Sausgruber (2005), Bicchieri amd Xiao (2009), Servátka (2009), Gächter, Nosenzo and Sefton (2012), or Gürerk (2012).
} 
identical to those in the Contract Choice Experiment. The only difference is that not the principal but now the agent sees a table similar to one in the Norms treatment with efforts of 10 selected employees from a previous experiment. ${ }^{18}$ We ran two different treatments: Selfish Norm and Prosocial Norm. For each of the two treatments we selected a different sample of actual effort contributions from the Baseline treatment of our first experiment. In the Prosocial Norm treatment we displayed a sample of 10 selected agents with very high contributions under the trust contract. The average effort of the selected sample was 60.1 under the trust contract and 47.9 under the contingent contract. To obtain a ceteris paribus comparison we deliberately selected for each displayed agent in the Prosocial Norm treatment a counterpart (also from the real observations in the Baseline setting) with nearly the same effort under the contingent contract but a substantially lower contribution for the trust contract. The actions of these 10 agents with average efforts of 19 under the trust contract and 47.1 under the contingent contract were presented to the subjects in the Selfish Norm treatment. ${ }^{19}$ The principals knew that the agents could see the decisions of the 10 selected agents from the previous sessions but didn't know the efforts themselves. The agents were aware that principals knew that the agents had been provided with this information.

In total 120 subjects took part in this experiment (30 in role of employer and 30 in role of employee in each treatment). The experiment lasted about one hour. All payments were made individually and anonymously. The average earnings were $10.57 €$ per subject.

\footnotetext{
18 We intentionally spoke of "selected agents" to avoid deception but made no information available on the specific selection procedure.

19 The exact individual values are reported in Table A2 in the Appendix 1.
} 


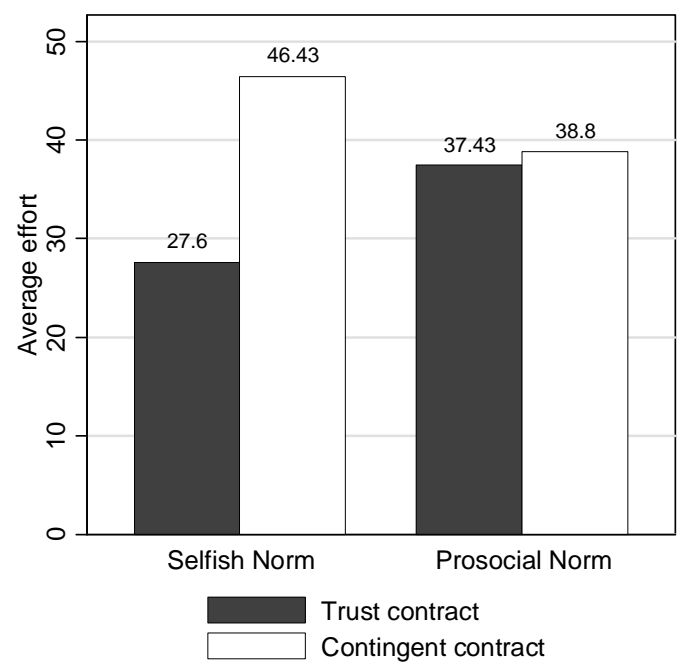

FIGURE 4: AVERAGE EFFORTS IN THE INDUCED NORM TREATMENTS

Results - As shown in Figure 4 we observe by $35.62 \%$ (and weakly significantly) higher average efforts for the trust contract in the Prosocial Norm treatment (37.43) than in the Selfish Norm treatment $(27.6, p=0.0547$, one-sided MWU test). There is no significant difference under the contingent contract in the Selfish Norm (46.43) treatment compared to the Prosocial Norm treatment (38.8, $p=0.3396$, two-sided MWU test). The within-subjects difference in the effort choices for the respective contracts is highly significant in the Selfish Norm treatment $(p=0.0044)$ but not in the Prosocial Norm treatment ( $p=0.8933$, both two-sided WSR test). Moreover, the betweentreatment difference in the span of efforts under the contingent and trust contract is highly significant ( $p=0.0129$, two-sided MWU test). ${ }^{20}$

$$
20
$$

Interestingly, average efforts in the Norms treatment of the Contract Choice Experiment are larger than in this (Induced) Prosocial Norm treatment (this difference is not significant but still sizeable). There may be two explanations for this: On the one hand this could be an indication that the contract choice ist the Norms treatment is a stronger signal than the observed prosocial norm because the trust contract is rather risky and choosing it implies that the principal has observed many very prosocial types. But it may also be due to the fact that we have shown the agents a selection of other agents and told them so in oder to avoid deception. If some agents anticipated that this was a positive selection they may have reacted to a weaker extent to this information. 
To sum up, we indeed find evidence for the two linkages in the conjectured mechanism (i) beliefs about the behavior of others are affected by knowledge about the contract choice of an informed principal and (ii) the agents' behavior is also affected by directly induced norms through information about the behavior of other agents.

\section{Varying the Context and Signal Strength}

So far we investigated the key hypothesis that contract choices lead to substantially different reactions on the part of the agents when principals had more information about the behavior of other agents prior to their choice. We considered a framework in which one action of a principal (choosing a trust contract in a setting where a majority of individuals expects a contingent contract) leads to a strong revision of initial beliefs. We now check the robustness of our results in a different context. In particular, we study the consequences of the mechanism in a framework where trust is a more frequent and thus less surprising choice and thus may be a weaker signal of prior knowledge of an informed principal.

We do this in two ways. First of all we apply our "norms intervention" to a treatment from the well-known "Cost of Control" experiment by Falk and Kosfeld (2006) in which the "controlling" contract choice is less appealing. In a second step we replicate our own initial experiment but reduce the attractiveness of the contingent contract by imposing costs on its choice for the principals. Both additional experiments allow us to study variations in the informational content of the contract choice as a signal about social norms of behavior.

\section{A. The Restriction Game}

Design and Procedure - In this experiment we replicated the "C10" treatment from Falk and Kosfeld (2006). An agent (Participant A) is matched to a principal (Participant $B$ ) and receives 120 points (in our setting equivalent 
to $12 €)$. The agent has to decide on a transfer $X$ subtracted from his own account that is doubled and added to the principal's account. Prior to the agent's choice the principal decides whether or not to impose a lower boundary of 10 on the agent's choice set. Hence, the principal choose $r \in\{0 ; 10\}$ and the agent $X \in\{r ; 120\}$ with payoffs $(120-X)$ for the agent and $(2 X)$ for the principal. As in the previous experiment (and as Falk and Kosfeld (2006) in their core treatments), we elicite agents' decisions via the strategy method.

We ran two treatments. The Baseline treatment is an exact replication of the Falk and Kosfeld (2006) "C10" setting also using their original instructions. ${ }^{21}$ The Norms treatment again uses the method introduced in the Contract Choice Experiment: Before making a decision, principals are informed about exact contributions of 10 agents from a prior (baseline) session and agents know that principals receive this information without knowing the exact data. Including $2.50 €$ show-up fee, the average earnings were $9.59 €$. In total 60 participants took part in the Baseline treatment and 56 in the Norms treatment. The experiment lasted about an hour.

We still expect that having principals who are informed about the norms make a difference. But here, not imposing the bound should be a weak signal of a "trustworthy" social norm as the imposed boundary on the agents' choices is relatively low and potential performance gains from imposing the restriction should be weak. But imposing the boundary may now become a more negative signal on the norm as it reveals that the principal apparently observed many selfish agents who chose an effort of less than 10 without the restriction.

Results - Within both treatments we find a qualitatively similar picture as obtained in Falk and Kosfeld (2006): the restriction does not increase and may

\footnotetext{
21 See Ziegelmayer, Schmelz and Ploner (2012), and Hagemann (2007) for the impact of the wording of the instructions on choices in the restriction game.
} 
even decrease efforts. ${ }^{22}$ The result of the treatment comparison is shown in Figure 5. Comparing the effort reaction between the Baseline Restriction Game (22.17) and the Norms variant (16.18), we find some (albeit not very strong) evidence for the hypothesis that when the restriction is imposed efforts are smaller in the Norms treatment ( $p=0.0896$ one-sided MWU test). ${ }^{23}$ But more interestingly, while the difference in individual contributions with and without restriction is not significant in Baseline $(p=0.1573)$ there is a highly significant difference in the Norms treatment $(p=0.0063$, both one-sided WSR tests). Hence, we here observe significant net crowding-out effects of "control" only if the control choice is made by a principal who has observed the behavior of other agents before.

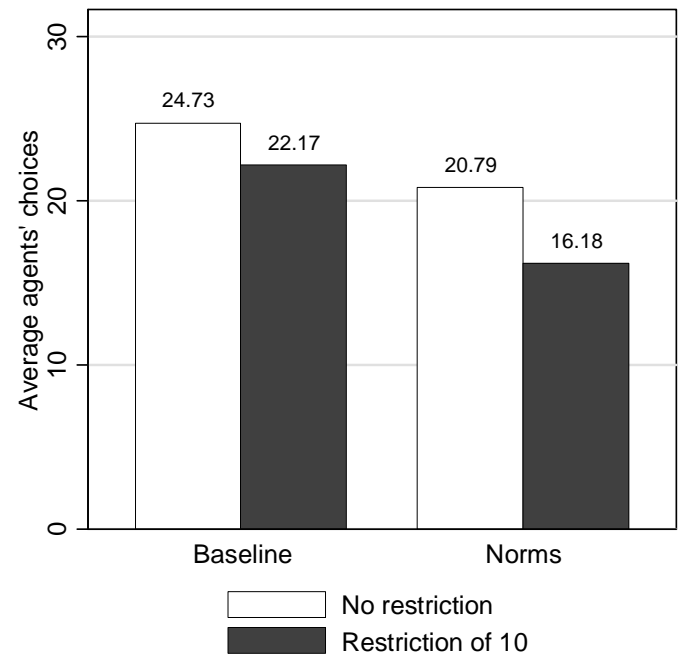

FIgURE 5: AVERAGE EFFORT CHOICES IN THE RESTRICTION GAME

\footnotetext{
22 with Falk and Kosfeld (2006) we find substantial "costs of control" in both treatments. If we - following their approach - impose the minimum of 10 on the effort data in the trust setting and compare it with contributions in the control setting the first variable is significantly higher in both treatments ( $p \leq 0.0016$, one-sided WSR test). Thus, many subjects choose lower efforts when being controlled than when being trusted.

23 For cumulative distributions of agents' choices see Figure A1 in the Appendix 1.
} 
Moreover, the results show that having an informed principal does not have a positive impact on the effort when no restriction is imposed. The efforts are even smaller in the Norms treatment, but this difference is not significant (20.79 instead of 24.73, $p=0.2705$ two-sided MWU test). The absence of a positive effect of trust indeed hints to the previously suggested idea that here trust is a weaker positive signal of the social norm and this is probably mainly due to two reasons. First of all, it is substantially more often used in this setting (on average in about $45 \%$ of the cases across both treatments). But moreover, the alternative to impose a rather low restriction is not particularly attractive and thus avoiding it does not signal strong prosocial behavior of the observed agents. We explore this idea in more detail in the next section.

\section{B. Costly Contract Choice Experiment}

As suggested in the previous section, the relative attractiveness of a specific contract for the principals should affect its signaling value. In turn, it should have an effect on the strength of the agents' reaction to the contract choice. Indeed we observed that (i) having a principal who is informed about the norm leads to a substantially stronger positive reaction to trust in our initial experiment where trust is the more surprising alternative, and (ii) having an informed principal leads to a more negative reaction to distrust in the Restriction Game where trust is more common and thus a less positive signal. However, these two settings are of course not perfectly comparable as they differ in a number of respects. Hence, we return to our initial Contract Choice Experiment and vary this setting in order to be able to make a more clean treatment comparison to study the effects of a different signal strength.

Design and Procedure - This experiment is almost identical to the initial Contract Choice Experiment, i.e. principals again choose between a contingent contract and a fixed wage contract and agents choose their effort levels for both contract types. The only change is that the principals now have to bear additional costs of $2 €$ when choosing the contingent contract and the agents 
are aware of this. All other parameters remain unchanged. We again conducted a Baseline treatment with no information on the behavior of others and a Norms treatment where before making their decisions principals learn about the behavior of agents in a Baseline session and the agents know this. The experiment lasted about an hour and 56 subjects took part in each of the two treatments (28 in the role of principal and 28 in role of agent). The average earnings were $9.79 €$ (including $2.50 €$ show-up fee).

It is important to note that in this experiment we changed the relative attractiveness of the contracts for the principal without altering the payoff structure for the agents. Hence, from the principal's point of view the contingent contract should become less attractive as compared to the initial experiment. Suppose, for instance, that principals play a best response to the observed behavior in the Norms treatment and thus choose a fixed wage contract if they observe that sufficiently many agents in the prior Baseline treatment had chosen high efforts under this contract. When the contingent contract is costly, a lower number of fair agents (i.e. those who had exerted high efforts under the fixed wage contract) suffices in order to make the principal select this fixed wage contract. Hence, the choice of the trust contract should be a weaker signal on a cooperative social norm and - if conformity matters - should lead to a weaker increase in efforts as compared to the initial experiment. But by the same token, the choice of a contingent contract may now be a more negative signal about the behavior observed by the principal as a higher degree of observed "selfishness" is necessary in order to induce a principal to choose the costly contingent contract.

Results - Average efforts are presented in Figure 6. First of all, we again find a significant effect of the Norms treatment on the contributions under the trust contract (41.82 compared to 28.5, $p=0.045$, one-sided MWU test). Hence, our key result that the trust contract is a positive signal of a prosocial norm and leads to higher efforts is qualitatively robust. But we now observe lower efforts under the contingent contract in the Norms treatment than in the 
Baseline (34.96 compared to 46.93, $p=0.023$, one-sided MWU test). ${ }^{24}$ This is in line with the observation made in the Restriction Game: The fact that an informed principal chooses the costly contingent contract apparently signals that the observed trustworthiness of the agents is rather low and, in turn, agents choose lower effort levels. ${ }^{25}$

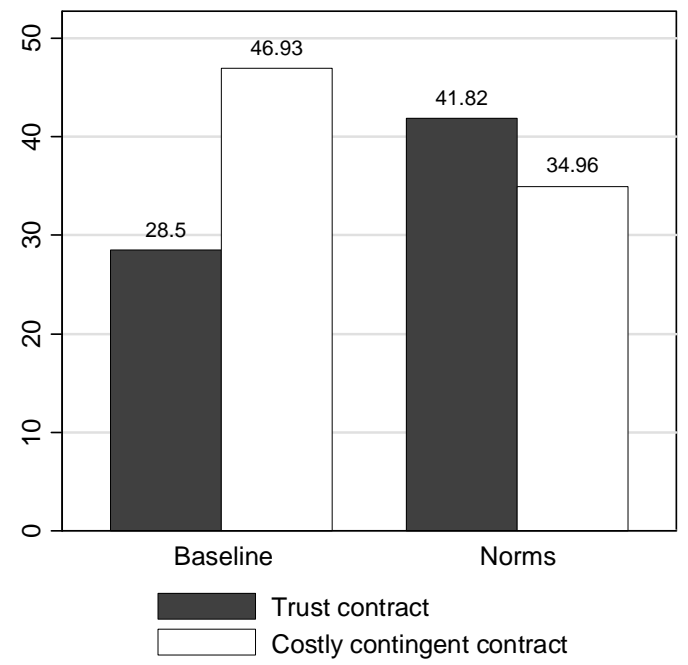

FiguRE 6: AVERAGE EFFORTS FOR THE TRUST CONTRACT AND CONTINGENT CONTRACT IN THE COSTLY CONTRACT CHOICE EXPERIMENT

We can also compare these results from the Costly Contract Choice Experiment to our initial (costless) Contract Choice Experiment. In the Baseline treatments of both experiments efforts are not significantly different

24 For a cumulative distribution of efforts see Figure A2 in the Appendix 1.

5 Further results are that expected principals' profits are significantly lower under the trust contract than under the contingent contract in the Baseline treatment (4.42€ compared to 7.28€, $p=0.0002$, two-sided WSR test), but there is no longer a significant difference in profits in the Norms treatment $(6.02 €$ compared to $6.45 €, p=0.5090$, two-sided WSR test). Moreover, in both treatments overall welfare is higher with a trust contract. Although the increase in expected welfare from choosing the trust contract instead of the contingent contract is only $0.64 €$ in the Baseline treatment, it is $2.39 €$ in the Norms treatment and this difference is highly significant $(p=0.0026$, two-sided MWU test). 
from each other. ${ }^{26}$ However, effort reactions are indeed significantly different in the Norms treatment. As conjectured, under both contract types agents exert lower efforts than in the initial experiment (under the trust contract 41.82 instead of 52.87, $p=0.047$ and under the contingent contract 34.96 instead of 48.60, $p=0.042$, both one-sided MWU test). Hence, reducing the attractiveness of the contingent contract indeed leads to a shift in its signaling value. And this shift reduces efforts for both contracts: (i) The trust contract is now a weaker signal of a prosocial norm as it chosen more often. Its choice is now apparently optimal for the principal also in situations when observed behavior is more selfish and this can explain why the induced increase in efforts is weaker as compared to the initial Contract Choice experiment. And (ii), by the same token, the choice of the contingent contract is now more likely a negative signal, because it apparently reveals that the principal has observed a rather selfish population. In turn, selfish behavior should appear more acceptable and thus agents may be driven to act more selfishly. ${ }^{27}$

Finally, these last observations are useful to discuss a potential alternative explanation for the key result of this paper. Namely, one difference between the initial Baseline and the Norms treatment is that in the latter agents may perceive that principals can compare their own performance outcomes to the behavior of others. ${ }^{28}$ If agents try to avoid looking selfish in comparison to 26 Efforts are smaller under the trust contract ( 28.5 instead of 35.37$)$ and larger under the contingent contract
(46.93 instead of 42.57$)$ in the Costly Contract Choice Experiment but these differences are not significant
$(p=0.4164$ and $p=0.3101$, two-sided MWU test).
27 A futher interesting question is whether principals understood these signaling effects. It is important to note that
while our treatment variation is minor on the agent's side, two things are changed in the Norms treatment that affect
principal's behavior: (a) principals observe behavior of other agents and (b) they know that the agents are aware of
this. In order to have a clean comparison of the principals' behavior it would be necessary to vary (b) without varying
(a) which would lead to deception. Hence, we focus on the agent's side where treatment comparisons are clean.
Indeed principals observed rather selfish behavior in the Norms treatment and this made them more reluctant to trust.
Only $25 \%$ of the principals choose the trust contract form in the Norms treatment but $46 \%$ in the Baseline treatment.
However, there is some indication in the Restriction Game studied in the previous setting (where the restriction does
not help so much against selfish behavior) that principals may have understood the signaling effects: Here the fraction
of principals choosing not to impose a restriction is $53.57 \%$ in the Norms treatment and $36.7 \%$ in Baseline.
28 Note that principals did never learn their agents effort and agents were explicitly told that this was not the case.
Hence, direct effort comparisons are infeasible also in the Norms treatment. Nevertheless, such a motivation is
conceivable as agents were aware that principals learned whether the project was successful or not which also yields
some information on agents efforts. 
these other agents, this may also lead to higher efforts in the Norms settings irrespective of the information conveyed through the principal's choice. ${ }^{29}$ And indeed, in our first experiment efforts are on average higher in the Norms treatment also under the contingent contract (even though this difference is insignificant). But in the Costly Contract Choice Experiment and the Restriction Game efforts under the contingent contract/restriction are lower in the Norms treatment (where agents can be compared) than in the Baseline treatment (where this is not possible). Hence, the results cannot be driven by the fact that outcomes are comparable with expected outcomes of other agents but they must be driven by the information conveyed on the size of these efforts.

\section{Conclusion}

We have shown in a series of lab experiments that contract choices can convey information about the behavior of others previously observed by the contract designer, and this information has a substantial impact beyond the direct incentives effect of the contract. Individuals react very differently to an identical contract when they know that the contract choice is based on richer information about prior reactions of others. Contract choices thus reveal information about prevalent social norms and shape behavior also indirectly beyond the direct material incentives.

It is important to stress that in our experiments these effects occur even though agents' behavior is not observed by peers and that they even ex-post do not receive information on the distribution of choices. Hence, the mechanism relies on an apparent intrinsic tendency for conformity and not on technological complementarities or image concerns. It is thus applicable to and should be relevant for a broader number of contexts, namely, all situations

\footnotetext{
29 This would also be an indication for the importance of social norms but not for the norms- signaling effects of contracts.
} 
in which a first mover's choice can reveal information about behavior in a broader population which, in turn can affect the behavior of second movers beyond their direct economic motives.

Moreover, our further experiments reveal that the signaling effect works in two directions in our context: When there is a powerful incentive technology available, not using this alternative and trusting the agents is a strong signal by an informed principal that many people are trustworthy. And while being risky this indeed substantially increases the trustworthiness of the responders. Norms signaling thus leads to "hidden benefits of trust". If, on the other hand, the incentive technology is less efficient trusting the agents by not using the technology becomes a more attractive choice for contract designers. But this has the drawback that trust is a weaker positive signal and, more importantly, setting contingent incentives now reveals a worse social norm and thus creates "hidden costs of control". And indeed we find that Falk and Kosfeld's (2006) hidden costs of control are more detrimental when principals are better informed about social norms of behavior.

Our results also have implications for the design of incentive schemes in practice. A direct implication is that when employees (or citizens) are not well informed about norms of behavior but the designer of an incentive scheme (or a law) is, the choice of the scheme will most certainly have signaling effects as it reveals information about prevalent norms. Moreover, the set of feasible alternatives affects the signaling value of a contract choice. When, for instance, employees know that non-distorted high powered incentives are in principle easy to implement, not using this alternative is a strong signal that the social norm is to be trustworthy. If on the other hand a firm uses a rather "shaky" technology to monitor behavior, this may reveal that apparently many 
employees are selfish. Both effects should lead to the optimality of lower powered incentives as compared to a situation with symmetric information. ${ }^{30}$

Of course there are many important further questions that need to be addressed. A key challenge is to study the consequences of changes in incentive structures on social norms in field settings for instance by exploiting information from employee surveys or using lab experiments in firms to elicit social norms before and after a change (see, for instance, Burks and Krupka 2012 for an approach to elicit norms in firms). Moreover, in smaller firms or communities people may have rather precise information about norms of behavior in their direct environment of colleagues or neighbors but not on broader groups of all employees in a large firm or most members of a society. It seems important to study to what extend contract choices can affect norms of behavior in subgroups that can mutually observe each other.

To gain a deeper understanding of the interplay between contracts and social norms in organizations is an important field for further research. While it is often easy to change formal rules in organizations, changing the complex system of informal rules is typically a much more demanding endeavor. But, as we have pointed out in this study, changes in formal rules affect perceptions about informal rules of behavior and thus shape these social norms. If we aim at giving better advice to practitioners on how to optimally design incentives, these indirect effects should not be disregarded as they have a substantial potential to alter the way in which changes in the formal rules affect behavior and in turn the overall performance of organizations.

\footnotetext{
30 See Benabou and Tirole (2012), section 4, for a related discussion on "expressive law", i.e. the role of law in conveying a society's norms of behavior which may lead to the choice of "softer" laws in order to signal that for instance only very disreputable people do not follow the norm and, hence, the necessity to induce tough sanctions is low. See also the discussion in Bowles (2008).
} 


\section{REFERENCES}

Akerlof, George A. 1980. "A Theory of Social Custom, of which Unemployment may be One Consequence." The Quarterly Journal of Economics 94(4): 749-775.

Bardsley, Nicholas, and Rupert Sausgruber. 2005. "Conformity and reciprocity in public good provision.” Journal of Economic Psychology 26(5): 664-681.

Bénabou, Roland, and Jean Tirole. 2003. "Intrinsic and Extrinsic Motivation." Review of Economic Studies 70(3): 489-520.

Bénabou, Roland, and Jean Tirole. 2006. "Incentives and Prosocial Behavior." American Economic Review 96(5): 1652-1678.

Bénabou, Roland, and Jean Tirole. 2012. "Laws and Norms." IZA Discussion Paper No. 6290.

Berg, Joyce, John Dickhaut, and Kevin McCabe. 1995. "Trust, Reciprocity, and Social History." Games and Economic Behavior 10(1): 122-142.

Bernheim, B. Douglas. 1994. "A Theory of Conformity.” Journal of Political Economy 102(5): 841-877.

Bicchieri, Cristina. 2006. The Grammar of Society: The Nature and Dynamics of Social Norms. New York: Cambridge University Press.

Bicchieri, Cristina, and Erte Xiao. 2009. "Do the right thing: but only if others do so.” Journal of Behavioral Decision Making 22(2): 191-208.

Bowles, Samuel. 2008. "Policies Designed for Self-Interested Citizens May Undermine 'The Moral Sentiments': Evidence from Economic Experiments." Science 320(5883): 1605-1609.

Bradler, Christiane, Robert Dur, Susanne Neckermann and Arjan Non. 2013. "Employee Recognition and Performance: A Field Experiment", Mimeo Univeristy of Rotterdam.

Burks, Stephen V., and Erin L. Krupka. 2012. "A Multimethod Approach to Identifying Norms and Normative Expectations Within a Corporate 
Hierarchy: Evidence from the Financial Services Industry." Management Science 58(1): 203-217.

Clark, Andrew E. 2003. "Unemployment as a Social Norm: Psychological Evidence from Panel Data.” Journal of Labor Economics 21(2): 323-351.

Costa-Gomes, Miguel A., Huck, Steffen, and Georg Weizsäcker. 2012. "Beliefs and actions in the trust game: Creating instrumental variables to estimate the causal effect.” WZB Discussion Papers SP II 2012-302.

Ellingsen, Tore, and Magnus Johannesson. 2008. "Pride and Prejudice: The Human Side of Incentive Theory." The American Economic Review 98(3): 990-1008.

Elster, John. 1989. "Social Norms and Economic Theory." The Journal of Economic Perspectives 3(4): 99-117.

Falk, Armin, and Michael Kosfeld. 2006. "The Hidden Costs of Control." The American Economic Review 96(5): 1611-1630.

Fehr, Ernst., Urs Fischbacher, and Simon Gächter. 2002. "Strong reciprocity, human cooperation, and the enforcement of social norms." Human nature 13(1): $1-25$.

Fehr, Ernst, and Urs Fischbacher. 2004a. "Social norms and human cooperation." Trends in Cognitive Sciences 8(4): 185-190.

—. 2004b. "Third-party punishment and social norms." Evolution and Human Behavior 25(2): 63-87.

Fehr, Ernst, and Bettina Rockenbach. 2003. "Detrimental effects of sanctions on human altruism.” Nature 422(6928): 137-140.

Fischbacher, Urs. 2007. "z-Tree: Zurich Toolbox for Ready-made Economic Experiments.” Experimental Economics 10(2): 171-78.

Fischer, Paul, and Steven Huddart. 2008. "Optimal contracting with endogenous social norms.” The American Economic Review 98(4): 14591475.

Friebel, Guido and Wendelin Schnedler, 2011. "Team governance: Empowerment or hierarchical control." Journal of Economic Behavior \& 
Organization 78(1): 1-13.

Galbiati, Roberto, Karl Schlag, and Joël van der Weele. 2011. "Sanctions that signal: an experiment." Vienna Working Paper 1107.

Gächter, Simon, Daniele Nosenzo, and Martin Sefton. 2012. "The Impact of Social Comparisons on Reciprocity." The Scandinavian Journal of Economics 114(4): 1346-1367.

Gürerk, Özgür. 2012. "Social learning increases the acceptance and the efficiency of punishment institutions in social dilemmas.” MPRA Paper. University Library of Munich, Germany.

Hagemann, Petra. 2007. "What's in a Frame? On Demand Effects and Trust in Experimental Studies.” Manuscript. University of Cologne.

Huck, Steffen, Dorothea Kübler, and Jörgen Weibull. 2012. "Social norms and economic incentives in firms." Journal of Economic Behavior \& Organization.

Ichino, Andrea, and Giovanni Maggi. 2000. "Work Environment and Individual Background: Explaining Regional Shirking Differentials in a Large Italian Firm.” The Quarterly Journal of Economics 115(3): 10571090.

Irlenbusch, Bernd, and Dirk Sliwka. 2005. "Incentives, Decision Frames, and Motivation Crowding Out - An Experimental Investigation.” IZA Discussion Paper No. 1758.

Krupka, Erin L., and Roberto A. Weber. 2009. "The focusing and informational effects of norms on pro-social behavior." Journal of Economic Psychology 30(3): 307-320.

Krupka, Erin L., Stephen Leider, and Ming Jiang. "A meeting of the minds: Contracts and social norms." mimeo. University of Michigan.

Kübler, Dorothea. 2001. "On the Regulation of Social Norms." Journal of Law, Economics, and Organization 17(2): 449-476.

Lindbeck, Assar, Sten Nyberg, and Jörgen W. Weibull. 1999. "Social Norms and Economic Incentives in the Welfare State." The Quarterly Journal of 
Economics 114(1): 1-35.

Selten, Reinhard. 1967. "Die Strategiemethode zur Erforschung des eingeschränkt rationalen Verhaltens im Rahmen eines Oligopolexperimentes." In H. Sauermann (Ed.), Beiträge zur experimentellen Wirtschaftsforschung (pp. 136-168). Tübingen: J.C.B. Mohr (Paul Siebeck).

Servátka, Maroš. 2009. "Separating reputation, social influence, and identification effects in a dictator game." European Economic Review 53(2): 197-209.

Shchetinin, Oleg. 2009. "Contracting Under Reciprocal Altruism." SSRN eLibrary.

Sliwka, Dirk. 2007. "Trust as a Signal of a Social Norm and the Hidden Costs of Incentive Schemes.” The American Economic Review 97(3): 999-1012.

Stutzer, Alois, and Rafael Lalive. 2004. "The Role of Social Work Norms in Job Searching and Subjective Well-Being." Journal of the European Economic Association 2(4): 696-719.

Van der Weele, Joël. 2012. "The Signaling Power of Sanctions in Social Dilemmas.” Journal of Law, Economics, and Organization 28(1): 103-126.

Young, H. Peyton. 2008. "social norms." In The New Palgrave Dictionary of Economics, eds. Steven N. Durlauf and Lawrence E. Blume. Basingstoke: Palgrave Macmillan.

Ziegelmeyer, Anthony, Katrin Schmelz, and Matteo Ploner. 2012. "Hidden costs of control: four repetitions and an extension." Experimental Economics 15(2): 323-340. 


\section{Appendix 1 - Additional Tables and Figures}

\section{TABLE A1: EXPERIMENTAL AND TREATMENT OVERVIEW}

\begin{tabular}{|c|c|c|c|c|c|c|c|c|}
\hline \multirow{2}{*}{ Experiment } & \multirow{2}{*}{ Treatment } & \multirow[t]{2}{*}{$\mathrm{N}$} & \multicolumn{3}{|c|}{ Effort Trust Contract } & \multicolumn{3}{|c|}{$\begin{array}{c}\text { Effort Contingent (Control) } \\
\text { Contract }\end{array}$} \\
\hline & & & Mean & Median & SD & Mean & Median & $\mathrm{SD}$ \\
\hline \multirow{2}{*}{ Contract Choice } & Baseline & 30 & 35.37 & 30.5 & 28.57 & 42.57 & 43 & 18.65 \\
\hline & Norms & 30 & 52.87 & 60 & 31.62 & 48.6 & 49.5 & 26.65 \\
\hline \multirow{3}{*}{$\begin{array}{l}\text { Online Belief } \\
\text { Elicitation }\end{array}$} & Baseline & 60 & 36.4 & 33.5 & 28.24 & 53.22 & 50 & 18.25 \\
\hline & Contingent & 57 & 49.12 & 50 & 22.72 & 59.28 & 60 & 18.04 \\
\hline & Trust & 61 & 62.36 & 70 & 20.29 & 49.13 & 50 & 21.3 \\
\hline \multirow[b]{2}{*}{ Explicit Norms } & Selfish Norm & 30 & 27.6 & 23.5 & 24.59 & 46.43 & 49 & 21.83 \\
\hline & $\begin{array}{l}\text { Prosocial } \\
\text { Norm }\end{array}$ & 30 & 37.43 & 44.5 & 28.45 & 38.8 & 48 & 23.71 \\
\hline \multirow{2}{*}{ Restriction Game } & Baseline & 30 & 24.73 & 25 & 20.34 & 22.17 & 17.5 & 13.81 \\
\hline & Norms & 28 & 20.79 & 20 & 12.39 & 16.18 & 10 & 9.7 \\
\hline \multirow{2}{*}{$\begin{array}{l}\text { Costly Contract } \\
\text { Choice }\end{array}$} & Baseline & 28 & 28.5 & 25 & 25.83 & 46.93 & 50 & 16.91 \\
\hline & Norms & 28 & 41.82 & 50 & 24.5 & 34.96 & 33.5 & 24.56 \\
\hline
\end{tabular}

TABLE A2: INFORMATION DISPLAYED TO EMPLOYEES IN EXPLICIT NORMS EXPERIMENT

\begin{tabular}{|c|c|c|c|c|c|c|c|c|c|c|}
\hline Prosocial Norm Treatment & 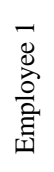 & 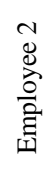 & 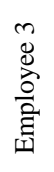 & 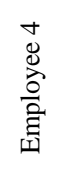 & 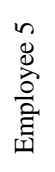 & 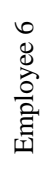 & 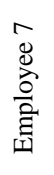 & 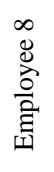 & 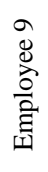 & 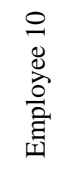 \\
\hline Effort trust contract & 70 & 60 & 80 & 100 & 25 & 25 & 60 & 51 & 60 & 70 \\
\hline Effort contingent contract & 60 & 41 & 50 & 77 & 10 & 38 & 70 & 48 & 25 & 60 \\
\hline Selfish Norm Treatment & 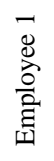 & 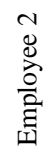 & 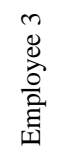 & 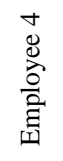 & 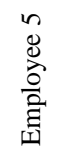 & 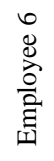 & 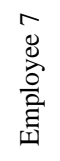 & 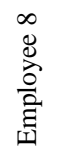 & 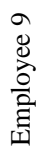 & 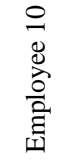 \\
\hline Effort trust contract & 34 & 0 & 27 & 35 & 10 & 18 & 0 & 11 & 20 & 35 \\
\hline Effort contingent contract & 60 & 45 & 51 & 70 & 10 & 38 & 65 & 49 & 25 & 58 \\
\hline
\end{tabular}




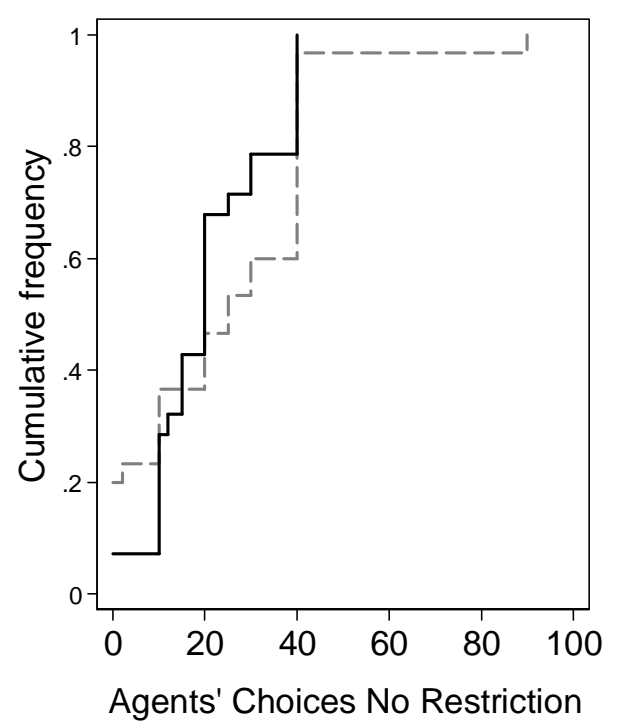

Baseline Norms

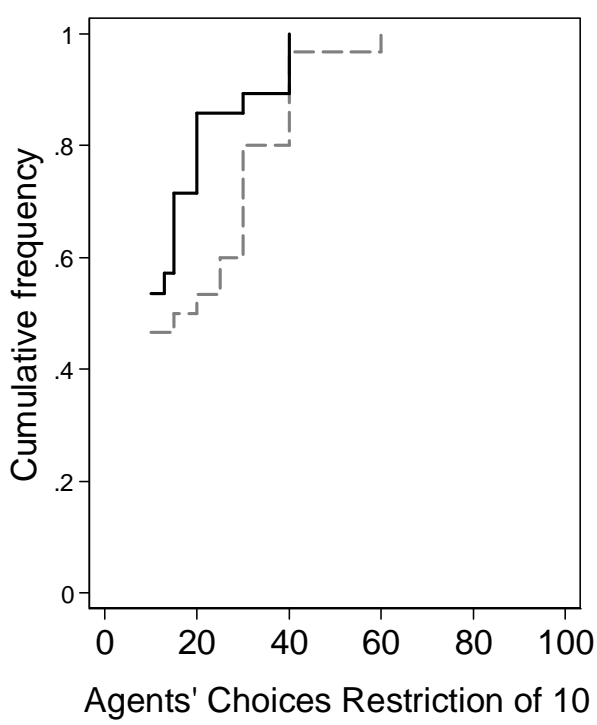

Baseline Norms

FIGURE A1: DISTRIBUTION OF CHOICES IN THE RESTRICTION GAME IN BASELINE AND NORMS
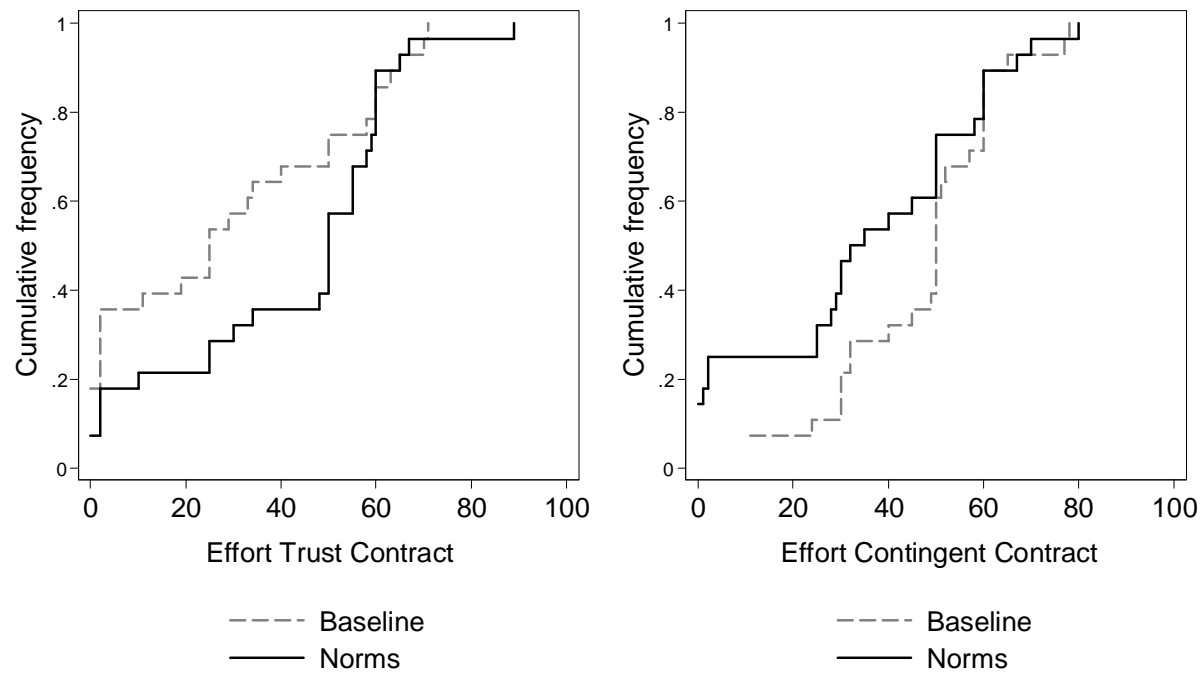

FIgURE A2: EFFORT DISTRIBUTION IN THE COSTLY CONTRACT CHOICE EXPERIMENT 
FIGURE A3: INFORMATION FOR EMPLOYERS IN THE NORMS TREATMENT (EXAMPLE)

\begin{tabular}{|c|c|c|c|c|c|c|c|c|c|c|}
\hline \multicolumn{11}{|c|}{ Here are decisions about effort from 10 participants from the last session of this experiment- who were in the role of employees: } \\
\hline & Employee 1 & Employee 2 & Employee 3 & Employee 4 & Employee 5 & Employee 6 & Employee 7 & Employee 8 & Employee 9 & Employee 10 \\
\hline $\begin{array}{l}\text { Effort under trust } \\
\text { compensation }\end{array}$ & 60 & 34 & 0 & 20 & 69 & 60 & 0 & 18 & 25 & 0 \\
\hline $\begin{array}{l}\text { Effort under contingent } \\
\text { compensation }\end{array}$ & 25 & 60 & 31 & 25 & 60 & 70 & 45 & 38 & 10 & 65 \\
\hline
\end{tabular}

FIGURE A4: INFORMATION FOR EMPLOYEES IN THE NORMS TREATMENT

Note:The employer has information about the efforts of 10 other employees from the previous experiment. But, he participates for the first time. The employer sees the following table where instead of $\mathrm{xx}$ are displayed the decisions of the employees from the past experiment:

\begin{tabular}{|c|c|c|c|c|c|c|c|c|c|c|}
\hline & Employee 1 & Employee 2 & Employee 3 & Employee 4 & Employee 5 & Employee 6 & Employee 7 & Employee 8 & Employee 9 & Employee 10 \\
\hline $\begin{array}{l}\text { Effort under trust } \\
\text { compensation }\end{array}$ & $x x$ & $x x$ & $x x$ & $x x$ & $x x$ & $x x$ & $x x$ & $x x$ & $x x$ & $x x$ \\
\hline $\begin{array}{l}\text { Effort under contingent } \\
\text { compensation }\end{array}$ & $x x$ & $x x$ & $x x$ & $x x$ & $x x$ & $x x$ & $x x$ & $x x$ & $x x$ & $x x$ \\
\hline
\end{tabular}




\section{Appendix 2 - On-Screen Experimental Instructions (translated from German)}

\section{<SCREEN 1> \\ INSTRUCTIONS}

Welcome and thank you for participating in today's experiment.

Please read the instructions carefully. If you have any questions don't hesitate to raise your arm. We will then come to your place and answer your question privately.

In today's experiment you can earn money. In the course of the experiment you interact with one other participant. The other participant is assigned randomly and anonymously, which means you will never learn about the other participant's identity. Neither will the other participant be informed about your identity.

The amount of your payment depends on your decisions as well as on the decisions of other participants. At the end of the experiment you will receive your payment in cash. In addition you receive a show-up fee of $2.50 €$ which is independent of the payment you receive from the experiment.

Communication is prohibited during the entire experiment. Please check if your mobile phone is turned off. A violation of these rules might lead to exclusion from this and any further experiments.

\section{<SCREEN 2>}

Please read the instructions carefully. You have to answer some questions afterwards in order to continue with the experiment.

You were chosen to be in the role of the employer/employee. The other participant with whom you interact is going to be the employee/employer.

Each participant receives an initial endowment of $6 €$ at the beginning of the experiment.

\section{PROJECT}

The employee is responsible for the success of a project. For the project the employee can choose an effort between 0 and 100 which causes costs for him/her depending on the level of effort. You can find the respective costs in the enclosed table.

The project's success probability is equal to the chosen level of effort. This means if the employee chooses an effort level X the project will be completed successfully in $\mathrm{X}$ out of 100 cases (this equals a probability of success of $\mathrm{X} \%$ ) and remains without success in $100-\mathrm{X}$ cases. 
If the project is completed successfully the employer receives a profit of $12 €$. In case of a failure the employer will receive an amount of $0 €$.

\section{DECISION OF THE EMPLOYER}

The employer decides about the form of compensation he wants to implement. $\mathrm{He}$ can select from the following compensation forms:

- Trust compensation: The employee receives an amount of $5 €$ from the employer independent of the project's success.

- Contingent compensation: The employee receives an amount of $5 €$ from the employer only in case of success. If the project is not completed successfully, the employee receives $0 €$.

\section{DECISION OF THE EMPLOYEE}

The employee chooses an effort level for each form of compensation.

Please note that the employer has no possibility to check the level of effort of his assigned employee.

\section{CALCULATION OF THE PAYMENT FROM THE PROJECT}

The payoff for the employer is equal to the profit generated by the project minus the amount which he has to pay the employee.

That means, if the employer chooses the trust compensation his payment is $12 €$ minus the wage costs of $5 €=7 €$ in case of a successfully completed project and otherwise $0 €$ minus the wage costs of $5 €=-5 €$.

If the employer decides to use the contingent compensation his payment is $12 €$ minus the wage costs of $5 €=7 €$ in case of a successfully completed project and otherwise $\underline{0 €}$.

The payoff for the employee is equal to the amount he receives from the employer minus the costs of effort.

That means, if the employer chooses the trust wage the payment of the

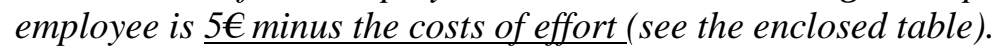

If the employer decides to use the contingent wage the employee receives $\underline{5 €}$ minus the costs of effort in case of a successfully completed experiment and otherwise $0 €$ with the costs of effort subtracted from his/her account.

Both the employer and the employee will not be informed about their payments from the project before the end of the experiment. 


\section{<SCREEN 3>}

\section{Questions to check the understanding of the experiment}

Please answer the following questions correctly to ensure that you have understood the experiment. If you have problems answering a question please contact the experimenter. The questions are illustrative and do not indicate the actual behavior of other participants.

\section{The experiment starts when each participant has answered all questions correctly.}

1. How much is the initial endowment?

2. Which amount does the employer get if the project is successful (excluding wage costs and the initial endowment)?

3. Which amount does the employer get if the project is not successful (excluding wage costs and the initial endowment)?

4. The project's success depends on the effort of the employee. (Yes/No)

5. The employee can choose an effort level between 0 and 100. (Yes/No)

6. What are the wage costs the employer has to pay if he chooses the trust compensation?

7. If the employer chooses the trust compensation he receives an amount of $12 €$ for sure. (Yes/No)

8. If the employer chooses the trust compensation the employee receives a salary of $5 €$ from the employer in any case. (Yes/No)

9. What is the amount the employee receives from the employer if the employer offers the contingent compensation and the project fails?

10. The employee's payment is equal to the payment from the employer minus the costs of effort (plus the initial endowment of $6 €$ ). (Yes/No)

11. The employer's payment is equal to the profit generated by the project $(0$ or $12 €)$ minus the wage costs contingent on the chosen type of wage form (plus the initial endowment of $6 €)$. (Yes/No)

$<$ Here the info-box with the instructions from the screen 2.>

<SCREEN 4 - Employer $>$

You are an employer.

$<$ Here additional information in the Norms treatment was displayed. See Figure A3 in the Appendix 1.>

\section{YOUR DECISION}

As employer you can decide which of the following forms of compensation you want to implement for your assigned employee:

- The trust compensation: „I, employer, select the trust compensation. As employee you receive an amount of 5.00€. This amount will be transferred to you from my account independent of the result of the project." 
- The contingent compensation: „I, employer, select the contingent compensation. As employee you can earn an amount of 5.00€. This amount will be transferred to you from my account only in case of a successful project."

Please note that the employee makes his/her decision about the level of effort for each form of compensation separately. He/she won't be informed about the form of compensation you actually have selected before he/she has made the decision. Relevant for your and the employee's payment is only the level of effort for the form of compensation which you have actually selected.

\section{Which form of compensation do you choose?}

- I choose the trust compensation.

- I choose the contingent compensation.

$<$ Here the info-box with the instructions from the screen 2.>

\section{<SCREEN 4 - Employee >}

You are an employee.

\section{$<$ Here additional information in the Norms treatment was displayed. See Figure A4 in the Appendix 1.>}

As an employee you have to decide about your level of effort. The employer chooses between a trust and a contingent compensation. Please state your level of effort now. You have to select your effort for both possible decisions of the employer. Afterwards you will be informed form of compensation your employer has actually chosen. After pressing the "Send" button the effort level you have typed in here is fixed. On this basis the project's probability of success and the payments will be calculated.

By pressing the "Calculate payment" button you can non-bindingly calculate your expected payment.

\section{<Here the sample calculator was displayed. See Figure on the next page.>}

Please note that this is your actual decision. You will be informed about the form of compensation the employer has selected at the end of the experiment. Depending on the selected form of compensation your decision about your level of effort will determine the project's probability of success and will therefore also be relevant for your payment and the payment of your employer.

\section{Calculate}


Which effort level do you choose if the employer selects the trust compensation: "I, employer, select the trust compensation. As employee you receive an amount of 5.00€. This amount will be transferred to you from my account independent of the result of the project."

Your level of effort for the trust compensation:

\section{Calculation of the payments under the trust compensation:}

The project's probability of success is (in \%): $\quad\langle\mathrm{xxx}\rangle$

Under the trust compensation you receive $5.00 €$ independent of the project's success.

For the effort you choose your payoff amounts to (in $€$ ): $\langle\mathrm{xxx}\rangle$

The employer receives $12.00 €$ in case of success and $0 €$ if the project is not successful.

The employer has to pay the wage costs of $5.00 €$ in any case.

For the effort you choose the expected payment to the employer amounts to(in $€)$ :

$\langle\mathrm{XXX}>$
Which effort level do you choose if the employer selects the contingent compensation: "I, employer, select the contingent wage. As employee you can earn an amount of 5.00€. This amount will be transferred to you from my account only in case of a successful project."

Your level of effort for the contingent compensation:

\section{Calculation of the payments under the contingent compensation:}

The project's probability of success is (in \%): $\quad\langle\mathrm{xxx}\rangle$

Under the contingent compensation you will receive $5.00 €$ in case of success and $0 €$ if the project is not successful.

For the effort you choose your expected payoff amounts to (in €):

$$
\langle\mathrm{xxx}>
$$

The employer receives $12.00 €$ in case of success and $0 €$ if the project is not successful.

He has to pay the wage costs of $5.00 €$ only if the project is successful. For the effort you choose the expected payment of the employer amounts to (in $€$ ): $\quad\langle x x x\rangle$ 


\section{<SCREEN 5 - Employer $>$}

Your payment from the first part of the experiment:

You have chosen the trust /contingent compensation.

The project was successful/not successful.

From this you receive $\mathbf{X}$ Euro.

The resulting wage costs are $\mathbf{X}$ Euro.

Additionally you get the initial endowment of 6 Euro.

Therefore your payment from this part of the experiment is $\mathbf{X}$ Euro.

$<$ SCREEN 5 - Employee $>$

Your payment from the first part of the experiment:

The employer has chosen the trust/contingent compensation.

You have selected an effort level of $\mathbf{e}$.

You have costs of X Euro.

The project was successful/not successful.

You receive a salary of 5.00 Euro.

Therefore your payment (including the in 